\title{
Tracheostomy in COVID-19 Patients: Experience at a Tertiary Center in the First 11 Months of the Pandemic
}

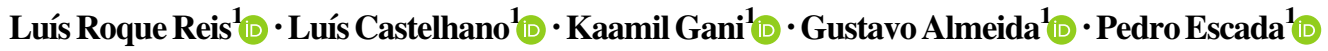

Received: 20 June 2021 / Accepted: 1 August 2021/Published online: 15 August 2021

(C) Association of Otolaryngologists of India 2021

\begin{abstract}
This study aimed to evaluate the experience of tracheostomy in COVID-19 patients in a Southern Europe tertiary hospital. Retrospective observational study in tracheostomized patients from April 1, 2020 to February 28, 2021. Data related to tracheostomy were evaluated in patients with and without COVID-19, including infections in healthcare professionals involved in patient care. Fortytwo tracheostomies were performed in COVID-19 patients aged $68.4 \pm 11.1$ years, predominantly men $(71 \%)$ and caucasians $(81 \%)$. They had at least 1 comorbidity $(93 \%)$, on average 3 . The most frequent were heart disease $(71 \%)$, age $>65$ years $(67 \%)$ diabetes $(40 \%)$ and obesity $(33 \%)$. The greater number of comorbidities was associated with the lesser probability of the patient's recovery $(p=.001)$. Age $(p=.047)$ and renal failure $(p=.013)$ were associated with higher mortality. Patients were tracheostomized by prolonged endo-tracheal intubation (50\%), pneumonia $(33 \%)$ and extubation failure $(10 \%)$. Ventilation time before the tracheostomy ( $22.9 \pm 6.5$ days) was higher than ventilation time after the tracheostomy $(7.1 \pm 15.1$ days $)$ $(p<0.001)$. No differences were found in ventilation time $(p=0.094)$ and tracheostomy time $(p=0.514)$ in the different indications. There were 3 minor complications (7.1\%), 25 discharges (60\%) and 11 deaths (26\%). During the same period 49 tracheostomies were performed in patients without COVID-19, with a homogeneous gender and age distribution, $31 \%$ without comorbidities, with an
\end{abstract}

Luís Roque Reis

roque-reis@sapo.pt

1 Department of Otorhinolaryngology, Egas Moniz Hospital, Centro Hospitalar de Lisboa Ocidental (CHLO), NOVA Medical School - Faculdade de Ciências Médicas, Rua da Junqueira, 126, 1340-019 Lisbon, Portugal average of 1 comorbidity per patient and higher mortality (43\%). Tracheostomy in COVID-19 patients proved to be a safe procedure for both patients and healthcare professionals and improves the clinical outcome of patients with severe infection. The 21-day procedure timing seems adequate. Comorbidities played an essential role in patient's recovery. Age and renal failure are associated with a worse vital prognosis.

Keywords COVID-19 · SARS-CoV-2 · Tracheostomy · Intubation · Invasive mechanical ventilation

\section{Introduction}

COVID-19 is the disease caused by the new coronavirus (SARS-CoV-2), which was first observed in December 2019 in Wuhan, China, and it quickly spread around the world. Because the virus is highly contagious, the World Health Organization (WHO) declared COVID-19 a pandemic on March 11, 2020. As of February 13, 2021, this pandemic has resulted in 110,609,979 confirmed cases and 2,452,510 deaths in 215 countries [1].

Epidemiological studies from different countries show that most infected patients are asymptomatic or have mild symptoms $(>80 \%)$, while $14 \%$ have a serious illness and need to be hospitalized [2-4]. Among hospitalized patients, the presence and severity of respiratory failure are usually the most important causes for intensive care unit (ICU) admission where patients receive ventilatory support (noninvasive or invasive ventilation) [4, 5]. Approximately $3-17 \%$ of hospitalized patients require invasive mechanical ventilation [6-9], and about $10 \%$ of patients who are admitted to the ICU will require prolonged intubation for 
more than 14 days [10]. In these cases, tracheostomy has been considered $[2,4,5,11-17]$.

The ideal time for tracheostomy in patients with COVID-19 has not been determined. Epidemiological data on the Portuguese National Health System's experience on this matter is also unknown. This represents a considerable knowledge gap, particularly after January 2021, when Portugal was the country with the highest number of new daily cases of SARS-CoV-2 infection per million inhabitants [18].

The aim of this study was to evaluate the experience of performing a tracheostomy in COVID-19 patients at a tertiary hospital center in southern Europe. The study evaluated patients' characteristics, clinical course, comorbidities, outcome, indications, and timing for tracheostomy. It also evaluated data from patients without COVID-19 who underwent tracheostomy in the same period. Finally, it checked whether there was a record of infection in the health professionals who were involved in these procedures.

\section{Methods}

This study was conducted in accordance with the Declaration of Helsinki and was approved by the Ethics Committee for Health (CES) at the Centro Hospitalar de Lisboa Ocidental (CHLO) no. 2142/21, Lisbon on May 26, 2021.

Patients were selected from the hospital's database, and their records were available through the Information Systems and Technologies Service (SSTI) at CHLO, EPE. All patients who underwent tracheostomy at the CHLO from April 1, 2020 to February 28, 2021 (11 months) were considered. Patients were admitted to the emergency department, which, since the beginning of the pandemic period, has operated under triage criteria that are specific for COVID-19, as defined by a national health regulation. Our emergency department provides health care to an estimated population of 439,944 inhabitants (based on the 2011 census). This is a region on the west coast of Portugal, with a predominantly Caucasian population, in which access to health care is universal but subject to payment (moderating fee) for medical care.

The time frame considered for this study was 11 months, from April 1, 2020 to February 28, 2021. The following data were collected: gender, age, previous medical history, presenting symptoms, comorbidities, period under mechanical ventilation, time from intubation to tracheostomy, time from tracheostomy to decannulation, complications, mortality, and length of hospital stay. Ventilator release was defined as the first full 24-h period without assisted mechanical ventilation. Several comorbidities that reflect the most serious findings of the disease that were reported in the literature have been studied, and are as follows: heart disease, respiratory disease, age, diabetes, and renal failure. A body mass index (BMI) greater than $30 \mathrm{~kg} / \mathrm{m}^{2}$, which is defined as obesity by the WHO, was considered to be a risk factor.

The data were entered into a Microsoft Excel ${ }^{\circledR}$ spreadsheet, and statistical analysis was performed using the Statistical Package for the Social Sciences ${ }^{\circledR}$ (SPSS) version 26.0 for Microsoft Windows ${ }^{\circledR}$ created by IBM, Illinois, Chicago, USA.

In a first phase, we tested the assumptions for the use of parametric tests to choose the most appropriate tests. All data were checked for normal distribution and homogeneity, and the appropriate statistical tests were selected based on the results. The Kendall's tau-b correlation coefficient was used to test the correlation between the number of comorbidities and the outcome (recovered/died), and the Chi-square test was used to assess the relationship between each comorbidity and the outcome. The Wilcoxon test was used to compare mechanical ventilation time before and after tracheostomy.

To mitigate viral transmission during this aerosol-generating surgical procedure, tracheostomies were performed in accordance with the recommendations of the Portuguese Society of Otorhinolaryngology and Head and Neck Surgery, which included the use of appropriate personal protective equipment (PPE), minimizing the number of people present in the operating room, and the use of a negative room pressure [19]. All tracheostomies were open surgeries (no cricothyroidotomies were performed) that were performed by 11 surgeons at the two hospitals that comprise the CHLO. The authors verified if there was any record of an infection in the health professionals who were involved in the procedures. Because most of the patients did not experience viral elimination 21 days after the onset of symptoms (although viral detection may not truly reflect the patient's infectious potential) [11, 12], it was institutionally decided to avoid tracheostomy before 21 days of endotracheal intubation. This timing was decreased in cases where intensivists justified that tracheostomies should be performed earlier for reasons such as the need for a pulmonary toilet or to reduce and suspend sedation.

\section{Results}

From April 1, 2020 to February 28, 2021, 101 tracheostomies were performed, 42 of which in patients with COVID-19 (Table 1). The patients were predominantly male (30 patients, $71 \%$ ), with an average age of $68.4 \pm 11.1$ years (range between 47 and 90 years). Thirty-four patients were caucasian $(81 \%)$, which can be explained by the demographic composition of the 
Table 1 Characteristics of patients with COVID-19 undergoing tracheostomy

\begin{tabular}{ll}
\hline Characteristics & $\mathrm{n}=42$ \\
\hline Age (years) & $68.4 \pm 11.1$ \\
Male (number and \%) & $30(71 \%)$ \\
Caucasian (number and \%) & $34(81 \%)$ \\
Comorbidities & \\
Heart disease (number and \%) & $30(71 \%)$ \\
Age > 65 years (number and \%) & $28(67 \%)$ \\
Diabetes (number and \%) & $17(40 \%)$ \\
BMI > 30 (number and \%) & $14(33 \%)$ \\
Renal insufficiency (number and \%) & $11(26 \%)$ \\
Chronic respiratory disease (number and \%) & $9(21 \%)$ \\
Others (number and \%) & $5(12 \%)$ \\
\hline
\end{tabular}

BMI: body mass index

institution's area of influence. Thirty-nine patients (93\%) had at least 1 comorbidity, with an average of 3 comorbidities per patient.

The most frequently reported comorbidities were heart disease (71\% of patients), diabetes $(40 \%)$ and obesity $(33 \%)$. Other rare and isolated comorbidities included HIV infection, low-grade non-Hodgkin's lymphoma, overlap syndrome (Sjogren/systemic sclerosis/polychondritis) and post-kidney transplant status. There was a moderate, positive and statistically significant correlation between the number of comorbidities and the outcome (recovery/death) $(\mathrm{rk}=0.44 ; p=0.001)$ : the greater the number of comorbidities, the lower was the patient likely to recover.

There was a statistically significant relationship between age comorbidity and the outcome and between renal failure comorbidity and the outcome. The results show that these two comorbidities are associated with a higher probability of death (Table 2). Although heart disease comorbidity was the most common in patients with tracheostomy, it was not found to be associated with a worse outcome.

Prolonged orotracheal intubation (OTI) was the most common indication for tracheostomy (21 patients, 50\%), followed by pneumonia (14 patients, 33\%), extubation failure (4 patients, 10\%) and vocal cords paresis (2 patients, 5\%) (Table 3).

At the date of the study, 25 patients $(60 \%)$ had been discharged and 6 remained hospitalized (Table 4). There were minor complications related to the procedure in 3 patients $(7.1 \%)$, which included hemorrhage (2 patients) and subcutaneous emphysema (1 patient).

The mean time of intubation before the tracheostomy, defined as the time from the first intubation to the tracheostomy, was $22.9 \pm 6.5$ days, with a range from 11 to 39 days. The 4 patients who failed extubation required
Table 2 Association between the comorbidities of patients with COVID -19 tracheostomized and the outcome (recovery/death)

\begin{tabular}{|c|c|c|c|c|c|c|}
\hline \multirow[t]{2}{*}{ Comorbidities } & \multicolumn{2}{|c|}{ Recovery } & \multicolumn{2}{|c|}{ Death } & \multirow[t]{2}{*}{$\chi^{2}$} & \multirow[t]{2}{*}{$p$} \\
\hline & $\mathrm{N}$ & $\%$ & $\mathrm{~N}$ & $\%$ & & \\
\hline Heart disease & & & & & 2.771 & .096 \\
\hline Yes & 20 & 64.5 & 10 & 90.9 & & \\
\hline No & 11 & 35.5 & 1 & 9.1 & & \\
\hline Chronic respiratory disease & & & & & 1.974 & .160 \\
\hline Yes & 5 & 16.1 & 4 & 36.4 & & \\
\hline No & 26 & 83.9 & 7 & 63.6 & & \\
\hline Age $>65$ years & & & & & 3.941 & .047 \\
\hline Yes & 18 & 58.1 & 10 & 90.9 & & \\
\hline No & 13 & 41.9 & 1 & 9.1 & & \\
\hline $\mathrm{BMI}>30$ & & & & & .062 & .804 \\
\hline Yes & 10 & 32.3 & 4 & 36.4 & & \\
\hline No & 21 & 67.7 & 7 & 63.6 & & \\
\hline Diabetes & & & & & 3.318 & .069 \\
\hline Yes & 10 & 32.3 & 7 & 63.6 & & \\
\hline No & 21 & 67.7 & 4 & 36.4 & & \\
\hline Renal insufficiency & & & & & 6.198 & .013 \\
\hline Yes & 5 & 16.1 & 6 & 54.5 & & \\
\hline No & 26 & 83.9 & 5 & 45.5 & & \\
\hline
\end{tabular}

BMI: body mass índex

Table 3 Indications for tracheostomies in patients with COVID-19

\begin{tabular}{ll}
\hline Indications for tracheostomies & $\mathrm{n}=42$ \\
\hline Prolonged OTI (number and \%) & $21(50 \%)$ \\
Pneumonia (number and \%) & $14(33 \%)$ \\
Extubation failure (number and \%) & $4(10 \%)$ \\
Vocal cords paresis (number and \%) & $2(5 \%)$ \\
Myopathy (number and \%) & $1(2 \%)$ \\
\hline
\end{tabular}

OTI: orotracheal intubation

reintubation before tracheostomy. The mean ventilation time after tracheostomy was $7.1 \pm 15.1$, with a range from 0 to 40 days. The average time from tracheostomy to decannulation was $27.5 \pm 19.8$ days, with a range from 3 to 99 days. The total time of assisted ventilation was $29.5 \pm 11.4$ days, with a range from 12 to 68 days.

The ventilation time before the tracheostomy was longer than the ventilation time after the tracheostomy $(\mathrm{Z}=-5.342 ; p<0.001)$. No differences were found in the ventilation time $(\mathrm{F}=2,288 ; p=0.094)$ and in the tracheostomy time $(\mathrm{F}=0.777 ; p=0.514)$ between the different indications. In these recovered patients, hospitalization ranged from 27 to 127 days $(60.2 \pm 31.6)$. 
Table 4 Clinical evolution of COVID-19 tracheostomy patients

\begin{tabular}{ll}
\hline Characteristics & $\mathrm{n}=42$ \\
\hline Discharged patients (number and \%) & $25(60 \%)$ \\
Admitted (number and \%) & $6(14 \%)$ \\
Recovered ( ${ }^{\circ}$ e \%) & $31(74 \%)$ \\
Total time of assisted ventilation (days) & $29.5 \pm 11.4(12-68)$ \\
Ventilation to tracheostomy time (days) & $22.9 \pm 6.5(11-39)$ \\
Ventilation time after tracheostomy (days) & $7.1 \pm 15.1(0-40)$ \\
Time with tracheostomy (days) & $27.5 \pm 19.8(3-99)$ \\
Mortality (number and \%) & $11(26 \%)$ \\
Ventilation to tracheostomy time (days) & $25.4 \pm 6(19-35)$ \\
Time with tracheostomy (days) & $7.6 \pm 5.3(2-20)$ \\
Length of hospital stay (days) & $32.6 \pm 9.4(19-55)$ \\
Complications (number and \%) & $3(7.1 \%)$ \\
\hline
\end{tabular}

In COVID-19 patients who underwent tracheostomy, the mortality rate was $26 \%$ (11 patients). In these patients the mean oral intubation time before tracheostomy was $25.4 \pm 6$ days, with a 19 to 35 days variation, the mean time of hospital stay, in these patients, was $32.6 \pm 9.4$ with a 19 to 55 days variation. There was no immediate postoperative or tracheostomy related deaths. In the patients that died, the mean time from tracheostomy to death was $7.6 \pm 5.3$ days with a variation from 2 to 20 days. In the recovered patients the length of hospital stay was from 27 to 127 days $(60.2 \pm 31.6)$.

During the 11 months studied, 49 non-COVID-19 related tracheostomies was performed (Table 5). The gender and age distribution were similar to the COVID-19 patients: 28 were male (57\%), 21 female (43\%), mean age $65 \pm 17.2$ years (variation 26 to 95 years), 44 patients were Caucasian (90\%). Fifteen patients $(31 \%)$ had no comorbidities, and there was a mean of 1 comorbidity per

Table 5 Characteristics of non-COVID-19 patients submitted to tracheostomy

\begin{tabular}{ll}
\hline Characteristics & $\mathrm{n}=49$ \\
\hline Age (years) & $65 \pm 17.2$ \\
Male (number and \%) & $28(57 \%)$ \\
Caucasian race (number and \%) & $44(90 \%)$ \\
Comorbidities & \\
Heart disease (number and \%) & $30(29 \%)$ \\
Age $>65$ years (number and \%) & $26(53 \%)$ \\
Diabetes (number and \%) & $17(24 \%)$ \\
BMI > 30 (number and \%) & $14(20 \%)$ \\
Chronic kidney failure (number and \%) & $3(6 \%)$ \\
Chronic lung illness (number and \%) & $5(10 \%)$ \\
\hline
\end{tabular}

BMI: body mass index patient. Besides advanced age (53\% of the patients), the more frequent were Cardiac illness (29\%), Diabetes (24\%) and Obesity (20\%).

Non-COVID-19 patients submitted to tracheostomy had a prolonged hospital stay ( $69.5 \pm 55.1$ days), in compare to the hospital stay in similar patients that didn't underwent tracheostomy (neurologic, tumoral, trauma and vascular) (Table 6). In these patients there was also a high mortality rate $(43 \%, 21$ patients). There were few tracheostomy related complications $(8.1 \%)$ that included post-operative bleeding in 3 patients and cannula exteriorization in 1 patient. Ventilation time form admission to tracheostomy was shorter than COVID-19 patients $(13 \pm 8.6$ days $)$, due to a precocious ICU indication, however the time with tracheostomy was longer ( $46.5 \pm 32.8$ days).

In our study there was viral transmission to any of the involved healthcare professional staff (surgical team or ward team).

\section{Discussion}

This study supports important conclusions about the use of tracheostomy in patients with COVID-19 because it included a considerable number of procedures that were performed since the beginning of the pandemic and for a considerable period of time, which included a time when Portugal was the country with the highest number of daily cases of SARS-CoV-2 infection per million inhabitants.

Table 6 Indications and clinical evolution of non-COVID-19 tracheostomy patients

\begin{tabular}{ll}
\hline Characteristics & $\mathrm{n}=49$ \\
\hline Indications & \\
Prolonged intubation (number and \%) & $25(51 \%)$ \\
Extubation failure (number and \%) & $7(15 \%)$ \\
ARDS (number and \%) & $5(10 \%)$ \\
Airway tumor (number and \%) & $5(10 \%)$ \\
Head trauma (number and \%) & $3(6 \%)$ \\
Vocal cord paralysis (number and \%) & $3(6 \%)$ \\
Radiotherapy (number and \%) & $1(2 \%)$ \\
Ventilation & \\
Total ventilation time (days) & $12 \pm 19.4$ \\
Admission to tracheostomy time (days) & $13 \pm 8.6$ \\
Time with tracheostomy (days) & $46.5 \pm 32.8$ \\
Time of hospital stay (days) & $69.5 \pm 55.1$ \\
Complications (number and \%) & $4(8.1 \%)$ \\
Mortality & $21(43 \%)$ \\
\hline ARDS: Acut
\end{tabular}

ARDS: Acute Respiratory Distress Syndrome 
During the study period, 42 tracheostomies were performed in patients with COVID-19, and 49 tracheostomies were performed in patients without COVID-19. Thus, the number of these procedures almost doubled because of the disease. This necessarily has consequences from an organizational point of view for otorhinolaryngology services and for operating theaters and the ICU to ensure that all patients who are candidates for tracheostomy and who are referred for the procedure undergo the procedure quickly.

Some comorbidities influence the prognosis of patients with COVID-19. Our study identified a higher rate of these comorbidities in patients with COVID-19 (mean of three comorbidities) compared to patients without COVID (mean of one comorbidity). The higher number of comorbidities were found to negatively influence patient recovery, and older age and renal failure were shown to be associated with higher mortality in these patients. However, the mortality of patients who undergo tracheostomy due to a disease other than COVID-19 was higher because of the underlying disease (e.g., neurological, trauma, or vascular reasons).

The advantages for tracheostomy in patients with prolonged intubation are the reduction of mechanical ventilation time [20], length of ICU stay [21], mortality [22], risk of developing subglottic stenosis [23], and use of sedation [21], and there is an improvement in the pulmonary toilet [24]. COVID-19 patients tend to stay longer in the ICU, and many of them remain intubated for 1 to 2 weeks or more [2]. The indications for tracheostomy in COVID-19 patients in our study were similar to those in non-COVID patients. Many patients do not attempt early weaning on assisted ventilation (for example, in the first week), although this does not appear to be a predictive factor in the inability to wean and extubate. However, some patients end up needing a tracheostomy $(<10 \%$ of ICU admissions) $[13,14,16,25]$. In our study, there was no higher rate of tracheostomy due to extubation failure in patients with COVID-19, nor were there any differences in ventilation and tracheostomy time on the basis of the indications.

Tracheostomies in patients with COVID-19 were performed $22.9 \pm 6.5$ days after endotracheal intubation, which was about 1 week after patients without COVID-19. The timing of the procedure was influenced by several factors, including recommendations of some scientific societies such as the Portuguese Society of Otorhinolaryngology and Head and Neck Surgery, which argues that tracheostomy should be performed only when considered absolutely necessary and as late as possible, ideally in a period without active infection (21). Tracheostomies that were performed by otorhinolaryngology were associated with better survival [17], and the timing of 21 days to perform the tracheostomy was considered to be adequate $[4,5,17,26]$.

In non-COVID patients, changes in practice have led intensivists to indicate tracheostomy on day 7 to 10 after initial intubation [20] to maximize ICU resource availability [15, 27]. In COVID-19 patients, although tracheostomy is feasible at the referred timing after initial intubation [28], it seems advisable to proceed beyond this period of time due to safety concerns for the healthcare professionals. The procedure can be considered before 21 days in exceptional situations of prolonged ventilator dependence, high risk of transmission, poor prognosis for intubated and ventilated patients [11-13, 29], greater need for pulmonary toilet, or high sedation levels [24].

In recovered patients, the tracheostomy time (from procedure to decannulation) was significantly shorter in patients with COVID-19 (27.5 \pm 19.8 days) compared to patients without COVID-19 (46.5 \pm 32.8$)$, which is a positive indicator of respiratory improvement in patients with COVID-19.

For the tracheostomies that were performed in both patients with COVID-19 and patients without COVID-19, the complication rate was low $(7 \%-8 \%)$, and the complications that were recorded were minor complications. The surgical teams had the option to perform the tracheostomies in an operating room with all the appropriate conditions for the positioning, comfort, and safety of patients and professionals and with the availability of all the required equipment and devices to perform the procedure and resolve any complications immediately.

Although the risk of coronavirus transmission to healthcare professionals is high during procedures such as tracheostomy (after endotracheal intubation, which has a higher risk, the odds ratio [OR] was 6.6, and for a noninvasive determination, the OR was 3.1 [30]), in our study, there was no transmission of the virus to health professionals. For all teams and all patients, all safety recommendations that were proposed by the authorities and national and international health societies of scientific research were followed.

The limitations of this study include the retrospective collection of medical records, which can affect the accuracy of the data. The data were collected by three researchers to increase its reliability. On the date of data collection, many patients remained hospitalized, and thus, results, complications, and mortality may be underreported.

\section{Conclusion}

Tracheostomy in COVID-19 patients is indicated in hospitalized patients with severe disease and prolonged orotracheal intubation. The procedure, which is performed 
after day 21 of endotracheal intubation, was shown to be safe and beneficial. In these patients, there was a mortality rate of $26 \%$, but the reason for death was not related to the procedure. There was also a low rate of complications, with only minor complications occurring in these patients.

The release of assisted ventilation was quick, and there were no safety problems for the health professionals who were involved in the procedure. Otorhinolaryngology services and operating rooms need to adapt to accommodate a significantly larger number of tracheostomies that need to be performed under more demanding safety conditions.

\section{References}

1. Organization WH WHO Coronavirus Disease (COVID-19) Dashboard. https://covid19.who.int. Accessed 21 Feb 2021

2. Grasselli G, Zangrillo A, Zanella A, Antonelli M, Cabrini L, Castelli A, Cereda D, Coluccello A, Foti G, Fumagalli R, Iotti G, Latronico N, Lorini L, Merler S, Natalini G, Piatti A, Ranieri MV, Scandroglio AM, Storti E, Cecconi M, Pesenti A, Network C-LI (2020) Baseline Characteristics and outcomes of 1591 patients infected With SARS-CoV-2 admitted to ICUs of the Lombardy region. Italy JAMA 323(16):1574-1581. https://doi .org/10.1001/jama.2020.5394

3. Anesi GL, Jablonski J, Harhay MO, Atkins JH, Bajaj J, Baston C, Brennan PJ, Candeloro CL, Catalano LM, Cereda MF, Chandler JM, Christie JD, Collins T, Courtright KR, Fuchs BD, Gordon E, Greenwood JC, Gudowski S, Hanish A, Hanson Iii CW, Heuer M, Kinniry P, Kornfield ZN, Kruse GB, Lane-Fall M, Martin ND, Mikkelsen ME, Negoianu D, Pascual JL, Patel MB, Pugliese SC, Qasim ZA, Reilly JP, Salmon J, Schweickert WD, Scott MJ, Shashaty MGS, Sicoutris CP, Wang JK, Wang W, Wani AA, Anderson BJ, Gutsche JT (2021) Characteristics, outcomes, and trends of patients with COVID-19-related critical illness at a learning health system in the United States. Ann Intern Med. https://doi.org/10.7326/M20-5327

4. Martin-Villares C, Perez Molina-Ramirez C, Bartolome-Benito M, Bernal-Sprekelsen M, Group COEC (2020) Outcome of 1890 tracheostomies for critical COVID-19 patients: a national cohort study in Spain. Eur Arch Otorhinolaryngol. https://doi.org /10.1007/s00405-020-06220-3

5. Volo T, Stritoni P, Battel I, Zennaro B, Lazzari F, Bellin M, Michieletto L, Spinato G, Busatto C, Politi D, Spinato R (2021) Elective tracheostomy during COVID-19 outbreak: to whom, when, how? Early experience from Venice. Italy Eur Arch Otorhinolaryngol 278(3):781-789. https://doi.org/10.1007 /s00405-020-06190-6

6. Huang C, Wang Y, Li X, Ren L, Zhao J, Hu Y, Zhang L, Fan G, Xu J, Gu X, Cheng Z, Yu T, Xia J, Wei Y, Wu W, Xie X, Yin W, Li H, Liu M, Xiao Y, Gao H, Guo L, Xie J, Wang G, Jiang R, Gao Z, Jin Q, Wang J, Cao B (2020) Clinical features of patients infected with 2019 novel coronavirus in Wuhan. China Lancet 395(10223):497-506. https://doi.org/10.1016/S0140-6736(20)30 183-5

7. Wang D, Hu B, Hu C, Zhu F, Liu X, Zhang J, Wang B, Xiang H, Cheng Z, Xiong Y, Zhao Y, Li Y, Wang X, Peng Z (2020) Clinical characteristics of 138 hospitalized patients With 2019 novel coronavirus-infected pneumonia in Wuhan. China JAMA 323(11):1061-1069. https://doi.org/10.1001/jama.2020.1585
8. Zhou F, Yu T, Du R, Fan G, Liu Y, Liu Z, Xiang J, Wang Y, Song B, Gu X, Guan L, Wei Y, Li H, Wu X, Xu J, Tu S, Zhang Y, Chen H, Cao B (2020) Clinical course and risk factors for mortality of adult inpatients with COVID-19 in Wuhan, China: a retrospective cohort study. Lancet 395(10229):1054-1062. https://doi.org/10.1016/S0140-6736(20)30566-3

9. Richardson S, Hirsch JS, Narasimhan M, Crawford JM, McGinn T, Davidson KW, the Northwell C-RC, Barnaby DP, Becker LB, Chelico JD, Cohen SL, Cookingham J, Coppa K, Diefenbach MA, Dominello AJ, Duer-Hefele J, Falzon L, Gitlin J, Hajizadeh N, Harvin TG, Hirschwerk DA, Kim EJ, Kozel ZM, Marrast LM, Mogavero JN, Osorio GA, Qiu M, Zanos TP, (2020) Presenting Characteristics, Comorbidities, and Outcomes Among 5700 Patients Hospitalized With COVID-19 in the New York City Area. JAMA 323(20):2052-2059. https://doi.org/10.1001/ jama.2020.6775

10. National Tracheostomy Safety Project. Multidisciplinary COVID-19 tracheostomy guidance.

11. Chao TN, Braslow BM, Martin ND, Chalian AA, Atkins J, Haas AR, Rassekh CH (2020) Guidelines from the Covid-19 tracheotomy task force aWGotASCotUoPHS, tracheotomy in ventilated patients with COVID-19. Ann Surg 272(1):e30-e32. https://doi.org/10.1097/SLA.0000000000003956

12. Chao TN, Braslow BM, Martin ND, Chalian AA, Atkins JH, Haas AR, Rassekh CH (2020) Response to comment on: tracheotomy in ventilated patients with COVID-19. Ann Surg. https://doi.org/10.1097/SLA.0000000000004162

13. Miles BA, Schiff B, Ganly I, Ow T, Cohen E, Genden E, Culliney B, Mehrotra B, Savona S, Wong RJ, Haigentz M, Caruana S, Givi B, Patel K, Hu K (2020) Tracheostomy during SARS-CoV-2 pandemic: recommendations from the New York head and neck society. Head Neck 42(6):1282-1290. https://doi.org/10. 1002/hed.26166

14. Turri-Zanoni M, Battaglia P, Czaczkes C, Pelosi P, Castelnuovo P, Cabrini L (2020) Elective tracheostomy during mechanical ventilation in patients affected by COVID-19: preliminary case series from Lombardy. Italy Otolaryngol Head Neck Surg 163(1):135-137. https://doi.org/10.1177/0194599820928963

15. McGrath BA, Brenner MJ, Warrillow SJ, Pandian V, Arora A, Cameron TS, Anon JM, Hernandez Martinez G, Truog RD, Block SD, Lui GCY, McDonald C, Rassekh CH, Atkins J, Qiang L, Vergez S, Dulguerov P, Zenk J, Antonelli M, Pelosi P, Walsh BK, Ward E, Shang Y, Gasparini S, Donati A, Singer M, Openshaw PJM, Tolley N, Markel H, Feller-Kopman DJ (2020) Tracheostomy in the COVID-19 era: global and multidisciplinary guidance. Lancet Respir Med 8(7):717-725. https://doi.org/ 10.1016/S2213-2600(20)30230-7

16. Goldman RA, Swendseid B, Chan JYK, Lewandowski M, Adams J, Purcell M, Cognetti DM (2020) Tracheostomy management during the COVID-19 pandemic. Otolaryngol Head Neck Surg 163(1):67-69. https://doi.org/10.1177/0194599820923632

17. Ahmed Y, Cao A, Thal A, Shah S, Kinkhabwala C, Liao D, Li D, Parides M, Mehta V, Ow T, Smith R, Schiff BA (2021) Tracheotomy Outcomes in 64 Ventilated COVID-19 Patients at a High-Volume Center in Bronx. Laryngoscope, NY. https://doi.org/10.1002/lary.29391

18. University JH (2021) Johns Hopkins Coronavirus Resource Center. https://coronavirus.jhu.edu/region/portugal. Accessed February 21, 20212021

19. Pedro Escada JoEiM, Sara Viana Baptista, Mariana Donato, Ricardo Santos, Jorge Spratley (2020) Recomendações para a realização de traqueotomia em doente com COVID-19. https://www.sporl.pt/traqueotomia. Accessed February 21, 2021

20. Griffiths J, Barber VS, Morgan L, Young JD (2005) Systematic review and meta-analysis of studies of the timing of tracheostomy 
in adult patients undergoing artificial ventilation. BMJ 330(7502):1243. https://doi.org/10.1136/bmj.38467.485671.E0

21. Liu CC, Livingstone D, Dixon E, Dort JC (2015) Early versus late tracheostomy: a systematic review and meta-analysis. Otolaryngol Head Neck Surg 152(2):219-227. https://doi.org/10 $.1177 / 0194599814561606$

22. Hosokawa K, Nishimura M, Egi M, Vincent JL (2015) Timing of tracheotomy in ICU patients: a systematic review of randomized controlled trials. Crit Care 19:424. https://doi.org/10. 1186/s13054-015-1138-8

23. Koshkareva Y, Gaughan JP, Soliman AM (2007) Risk factors for adult laryngotracheal stenosis: a review of 74 cases. Ann Otol Rhinol Laryngol 116(3):206-210. https://doi.org/10.1177/ 000348940711600308

24. Courtney A, Lignos L, Ward PA, Vizcaychipi MP (2021) Surgical Tracheostomy outcomes in COVID-19-positive patients. OTO Open. https://doi.org/10.1177/2473974X20984998

25. Queen Elizabeth Hospital Birmingham C-at (2020) Safety and 30-day outcomes of tracheostomy for COVID-19: a prospective observational cohort study. $\mathrm{Br} J$ Anaesth 125(6):872-879. https://doi.org/10.1016/j.bja.2020.08.023

26. Thal AG, Schiff BA, Ahmed Y, Cao A, Mo A, Mehta V, Smith RV, Cohen HW, Ow TJ (2021) Tracheotomy in a high-volume center during the COVID-19 pandemic: evaluating the surgeon's risk. Otolaryngol Head Neck Surg 164(3):522-527. https://doi.org/10.1177/0194599820955174

27. Angel L, Kon ZN, Chang SH, Rafeq S, Palasamudram Shekar S, Mitzman B, Amoroso N, Goldenberg R, Sureau K, Smith DE,
Cerfolio RJ (2020) Novel percutaneous tracheostomy for critically ill patients with COVID-19. Ann Thorac Surg 110(3):1006-1011. https://doi.org/10.1016/j.athoracsur.2020.04. 010

28. Rosano A, Martinelli E, Fusina F, Albani F, Caserta R, Morandi A, Dell'Agnolo P, Dicembrini A, Mansouri L, Marchini A, Schivalocchi V, Natalini G (2021) Early Percutaneous Tracheostomy in Coronavirus Disease 2019: Association With Hospital Mortality and Factors Associated With Removal of Tracheostomy Tube at ICU Discharge. A Cohort Study on 121 Patients. Crit Care Med 49 (2): 261-270. doi:https://doi.org /10.1097/CCM.0000000000004752

29. Sommer DD, Engels PT, Weitzel EK, Khalili S, Corsten M, Tewfik MA, Fung K, Cote D, Gupta M, Sne N, Brown TFE, Paul J, Kost KM, Witterick IJ (2020) Recommendations from the CSO-HNS taskforce on performance of tracheotomy during the COVID-19 pandemic. J Otolaryngol Head Neck Surg 49(1):23. https://doi.org/10.1186/s40463-020-00414-9

30. Tran K, Cimon K, Severn M, Pessoa-Silva CL, Conly J (2012) Aerosol generating procedures and risk of transmission of acute respiratory infections to healthcare workers: a systematic review. PLoS ONE 7(4):e35797. https://doi.org/10.1371/journal. pone.0035797

Publisher's Note Springer Nature remains neutral with regard to jurisdictional claims in published maps and institutional affiliations. 